\title{
Implementation of Green Marketing Concept Through Social Media Activities: A Systematic Literature Review
}

\author{
Elnur Nabivi \\ e.nabivi@uw.edu.pl \\ https://orcid.org/0000-0002-5341-7921
}

Received: 14 November 2020/ Revised: 11 January 2021/ Accepted: 15 January 2021/ Published online: 19 February 2021

\begin{abstract}
The last century's industrial and technological development has led to the growth of environmental problems such as global warming, climate changes, water, air, and ground pollution. The awareness of modern consumers about these issues is growing, and companies respond by using "green marketing" strategies. Green marketing refers to the development and marketing of products that are considered environmentally safe. Furthermore, the extensive use of the Internet and increasing social media's importance in recent years forced brands to communicate with consumers in this way. In this study, these two mega-trends influencing contemporary consumer behavior were combined: social media and green marketing. Although several studies explored sustainable strategies of brands in the field of social media, this body of research has not been subjected to a review. The primary goal of the research is to determine the main topics covered in the literature. A systematic literature review was conducted to take up this goal, indicating 31 relevant publications from 21 journals published between 2010 and July 2020, for exploring the ways of implementing green marketing strategies through social networks. After analyzing collected data, four main topics covered in the literature body were extracted: general marketing strategies of brands, brand promotion strategies, determinants of consumer's green purchasing behavior, and raising environmental awareness. Based on the performed synthesis, the research gaps and fruitful directions for further research were formulated.
\end{abstract}

JEL classification: M30, M31

Keywords: green marketing, sustainability, social media, consumer behavior, systematic literature review

\section{INTRODUCTION}

Globally, 4.14 billion active digital consumers spend an average of 149 minutes per day on social networks (We are social \& Hootsuite, 2020). This number is more than one-third of users' total internet time. Compared to October of the previous year, the number of active users increased by $12.3 \%$ in October 2020 . Moreover, this number continues to increase day by day. The vast majority of users actively engage with social media content through likes, retweets, comments, and link clicks. Given the unprecedented reach of social networks, companies rely on social networks as a channel for successful marketing communication. Kumar et al. (2016) argue that company-generated content in social media can affect consumer behavior. Brands do not share 
only news about themselves with their followers; they also give importance to environmental factors by using these platforms. The growing importance of environmental issues such as global warming or environmental pollution forces brands to act on this subject. Furthermore, by creating a "good citizen" perception through social media content, brands can take cognizance of social and environmental issues.

In recent years, green marketing becomes an essential tool for sustainable business strategy. As a result, companies adopt green marketing practices to achieve better business performance in their strategies. Henion and Kinnear proposed the first definition related to green marketing in 1976: "concerned with all marketing activities that have served to help cause environmental problems, and that may serve to provide a remedy for environmental problems" (Dangelico \& Vocalelli, 2017). Green marketing is not only about promoting products or services with environmental characteristics. It includes various activities such as changes and modifications in production processes, advertising strategies, packaging, and increasing environmental awareness (Polonsky, 1994). Another highly accepted green marketing definition was provided by Fuller (1999): "the process of planning, implementing and controlling the development, pricing, promotion, and distribution of products in a manner that satisfies the following three criteria: (1) customer needs are met, (2) organizational goals are attained, and (3) the process is compatible with ecosystems".

A lack of review of green marketing strategies of brands in social media is the primary stimulation of this paper. This review aims to fill two comprehensive objectives. Firstly, to determine, assess, and summarize the outcomes of relevant articles studying green marketing activities through social networks. Simultaneously, due to this action, knowledge gaps in the literature will be detected, and the directions for further research will be pointed out.

The research questions for the systematic review are shown below.

RQ1: What are the main topics covered in the existing body of literature?

RQ2: What are the research gaps and directions for further research?

Thus, this research seeks to answer these questions by examining the articles studying the green marketing concept through social media activities. The structure of the paper is as follows. This research starts with a detailed description of the systematic literature review method used here. The following section details the main findings of the review, which is followed by the conclusion and directions for further research.

\section{METHODS}

The systematic literature review was performed, which is "a review of a clearly formulated question that uses systematic and explicit methods to identify, select, and critically appraise relevant research, and to collect and analyze data from the studies that are included in the review" (Moher et al., 2009). The most salient features of systematic reviews are using methods that limit bias, produce accurate conclusions. Systematic reviews are characterized by being comprehensive, methodical, and replicable. It is also considered an efficient and reliable methodology, especially when working with a big literature database. The tendency of a systematic review to be more transparent than other types of literature reviews makes it more preferred by researchers (Siddaway et al., 2019).

As a first step, studies included in this systematic review were identified by searching the Scopus database due to its broad coverage and multidisciplinary nature (Gusenbauer \& Haddaway, 2020). The search was aimed to identify articles linked to green marketing through social media activities from the marketing perspective. For this reason, a combination of words connected to these three core concepts was used to access the relevant articles. The following formula was used to access the requested articles: TITLE-ABS-KEY ("green marketing" OR "green" OR "sustainability" OR "sustainable" OR “environmentally-sustainable" OR "eco-friendly") AND 
TITLE-ABS-KEY ("social network" OR "social networks" OR "social media" OR "Instagram" OR "Facebook” OR “Twitter” OR "Linkedin” OR “digital marketing”) AND TITLE-ABS-KEY ("marketing" OR “consumer behavior" OR "consumer behaviour").

Only full-length, peer-reviewed papers published in the English language between 2010 and July 2020 were included in the screening process. The publication year delimiter was applied because of the widespread use and constant change of social media in recent years. This process excludes papers that are not in this context and brings 529 search results. All accessed papers were exported to Mendeley reference management software.

As a next step, papers were accurately analyzed according to title, abstract, and keyword. As a result of this action, 442 papers were excluded from further analysis. The chosen articles were read to check eligibility. Full-text copies were read twice to minimize bias and ensure rigor. After reading full-text copies, articles that were not in research interest and did not present sufficient data were excluded. These procedures helped to eliminate further 56 irrelevant articles. As a result of the screening and eligibility process, 31 articles from 21 journals remained. A flow chart of the selection process based on the PRISMA Statement (Moher et al., 2009) is presented in Figure 1.

\section{Figure 1}

Flow chart of the different phases of the selection process of systematic literature review

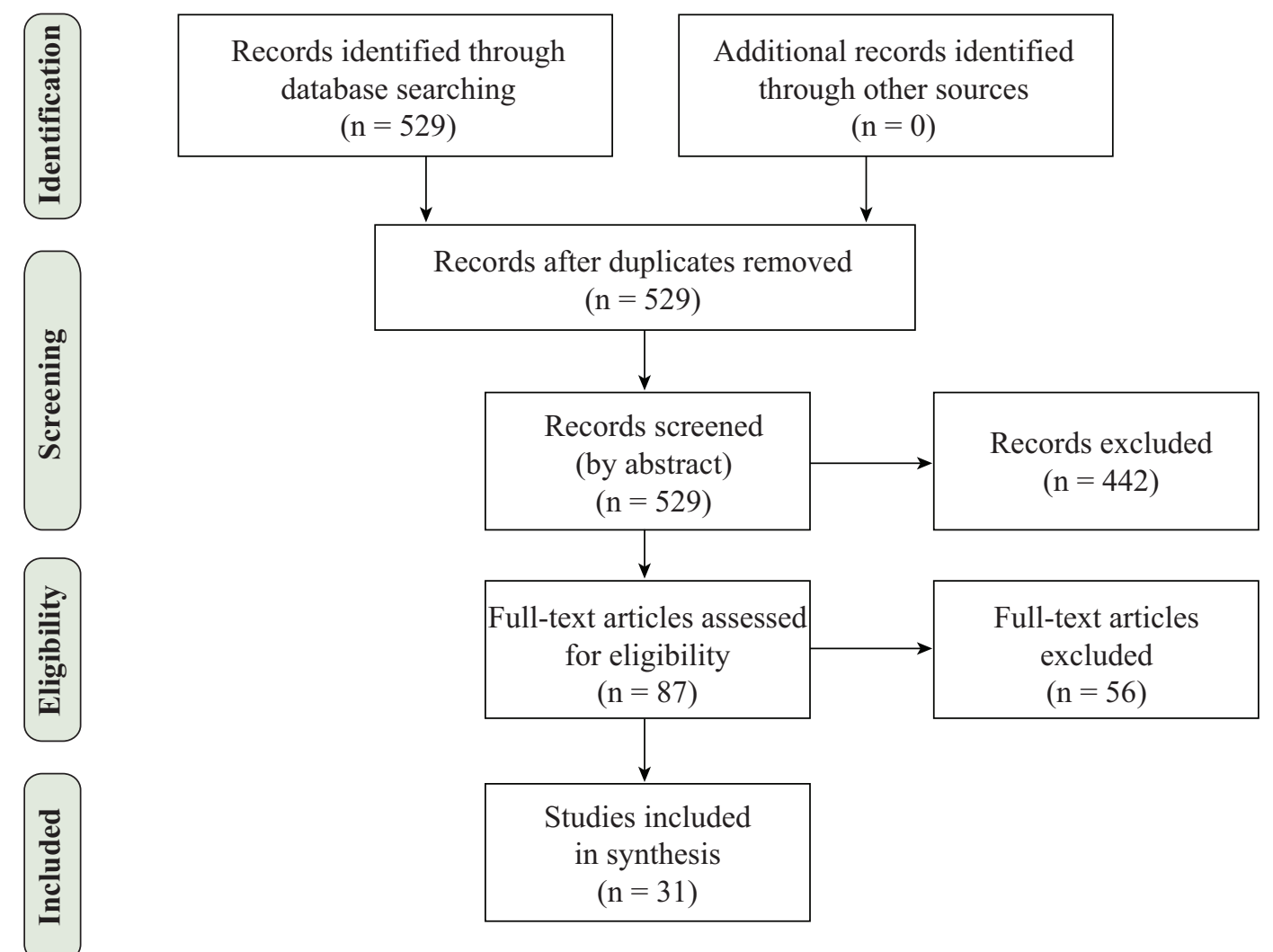

\section{FINDINGS}

To understand the overview of the research, SLR was employed by analyzing a total of 31 articles. This section summarizes and highlights key findings of the review carried out. First, bibliometric data such as the distribution of articles by journal, year of publication, and research context are presented. Afterward, the main thematic foci are synthesized. 


\subsection{Distribution of Articles by Journal}

Table 1 reports the number of articles included in the systematic literature review per each journal. "Sustainability" journal published eight studies included in the review. This is followed by "Business Strategy and the Environment" journal with three studies; "International Journal of Retail \& Distribution Management" with two studies. The articles included in the review were published in 21 different journals. According to the distribution of the articles, this subject mainly appeared in marketing journals.

Table 1

Number of articles included in the systematic literature review per each journal

\begin{tabular}{|c|c|}
\hline Journal Title & n \\
\hline Sustainability (Switzerland) & 8 \\
\hline Business Strategy and the Environment & 3 \\
\hline International Journal of Retail \& Distribution Management & 2 \\
\hline Environmental Communication & 1 \\
\hline Journal of Marketing Analytics & 1 \\
\hline Social Marketing Quarterly & 1 \\
\hline Journal of Air Transport Management & 1 \\
\hline Journal of Advertising & 1 \\
\hline Journal of Interactive Marketing & 1 \\
\hline Environmental Science and Pollution Research & 1 \\
\hline International Journal of Public Sector Performance Management & 1 \\
\hline Journal of International Consumer Marketing & 1 \\
\hline Asia Pacific Journal of Marketing and Logistics & 1 \\
\hline World Review of Entrepreneurship, Management and Sustainable Development & 1 \\
\hline Journal of Fashion Marketing and Management: An International Journal & 1 \\
\hline Corporate Social Responsibility and Environmental Management & 1 \\
\hline Journal of Cleaner Production & 1 \\
\hline Market-Trziste & 1 \\
\hline International Journal of Scientific and Technology Research & 1 \\
\hline Proceedings of the European Conference on Innovation and Entrepreneurship & 1 \\
\hline Handbook of Research on Developing Sustainable Value in Economics, Finance, and Marketing & 1 \\
\hline Total & 31 \\
\hline
\end{tabular}

\subsection{Distribution of Articles by Year of Publication}

The publication dates of a total of 31 articles are provided in Figure 2. According to the annual distribution of the articles, the number of articles linked to the green marketing concept through social media activities increased gradually after 2015. The peak year among the 31 articles was found to be 2019. This may be because of the increasing importance of green marketing and social media for both the consumers and the companies, which triggered more research interest among scholars. 
Figure 2

Distribution of articles by year of publication

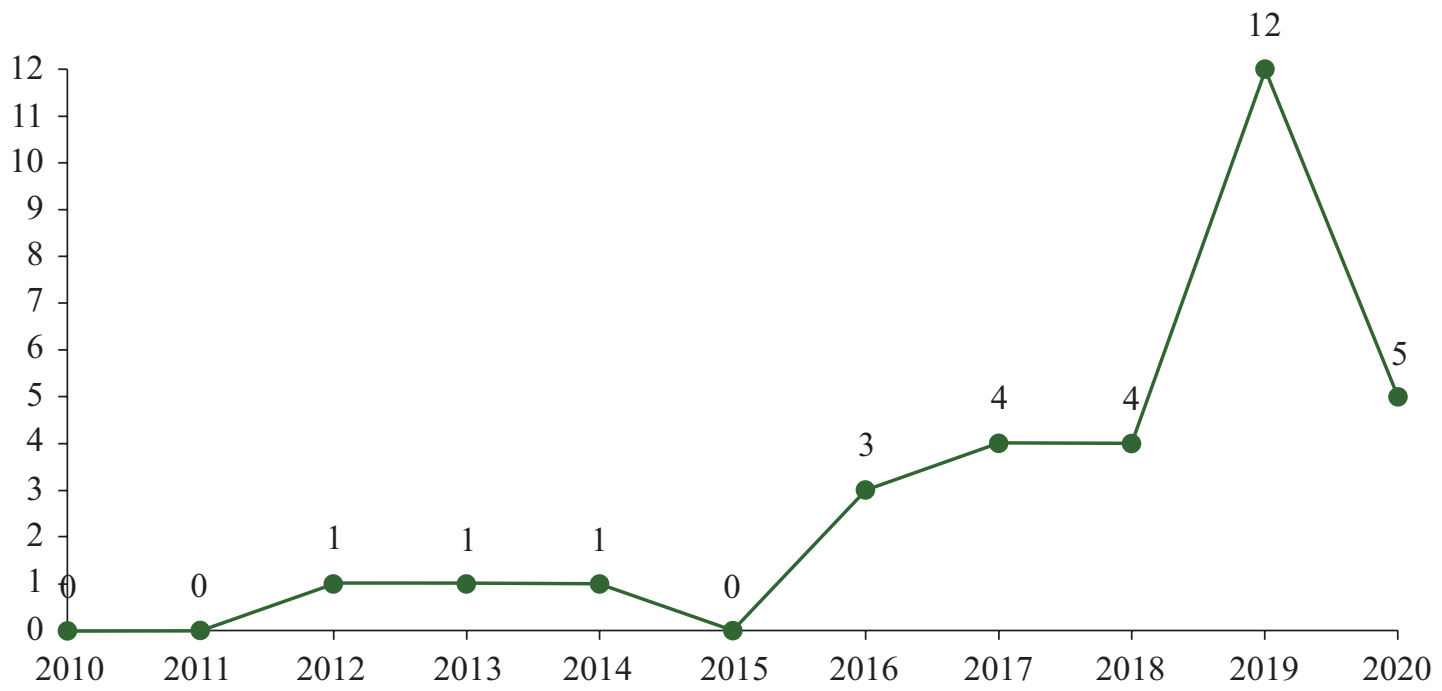

\subsection{Research Context}

Out of the 31 studies, three countries - the USA ( 6 articles), China (4 articles), and the UK (4 articles) -were predominantly examined in the review. This shows that most of the research on this topic is done in the largest economies. Collaboration between researchers is predominant; 29 of the articles are authored by two or more researchers. Only two studies are signed by one author (Byrum, 2019; Y.-C. Lee, 2017). The survey method was the most used research method among articles. 17 of the examined studies employed the survey method; archival data, multisource, and netnography are the other employed research methods, with 10, 3, and 1 studies, respectively.

\subsection{Thematic Foci}

The content analysis of the extracted 31 articles has led to the identification of four main thematic foci: general marketing strategies of brands, brand promotion strategies, determinants of consumer's green purchasing behavior, and raising environmental awareness. Table 2 presents the divisions of the papers into one of these four topics. Some articles were added to multiple categories due to overlapping research topics with more than one topic.

Eleven articles focused on brands' general marketing strategies on social media connected with green marketing activities. These articles include brands' sustainable strategies and brand sustainability associated with green marketing. The studies added to the raising environmental awareness thematic focus are mostly connected to Corporate Social Responsibility and about social media activities that aim to raise awareness of eco-issues. Twelve of the total number of articles were included in this category. Seven articles provided insights into the determinants of consumers' behavior while making sustainable purchases. Finally, four articles analyzed brands' promotion strategies. These articles are about the promotion strategies implemented by companies on social networking platforms. 
Table 2

Article classification by the thematic foci

General marketing strategies of brands

Determinants of consumer's green purchasing behavior

Brand promotion strategies

Raising environmental awareness
Abbas et al., 2019; Göçer \& Tuğrul, 2014; Hasbullah et al., 2020; Huang et al., 2019; Jones et al., 2013; Khan et al., 2019; Y.-C. Lee, 2017; Y.-K. Lee \& Park, 2016; Martínez-Navalón et al., 2019; Pilăr et al., 2019; Resnik \& Koklič, 2018

Byrum, 2019; Gandhi \& Sheorey, 2019; Gonzalez-Lafaysse \& Lapassouse-Madrid, 2016; Lu \& Miller, 2019; Sogari et al., 2017; Zahid et al., 2018; Zhao et al., 2019

Ahmed et al., 2019; Antonella et al., 2019; Gonzalez-Lafaysse \& Lapassouse-Madrid, 2016; Y.-K. Lee \& Park, 2016

Austin \& Gaither, 2016; Awais et al., 2020; Barboza \& Filho, 2019; Biswas \& Roy, 2018; Blasi et al., 2020; Kang \& Kim, 2017; Minton et al., 2012; Shen et al., 2020; Sogari et al., 2017; Topal et al., 2020; Vanko \& Zaušková, 2019; Young et al., 2018

\subsubsection{General marketing strategies of brands}

Social media strategies of brands play a substantial role in identifying current sustainable trends. Y.-C. Lee (2017) suggested a customer-centric framework to evaluate companies' corporate sustainability marketing strategies and analyzed strategy differences on Facebook and blogs. The main conclusion of this article is that there is a gap between the focus of enterprises and customers on social media. While enterprises attach importance to the promotion of sustainability, green products, and environmental protection topics, customers expect to see sustainable means, green production and service processes, and renewable energy topics. Moreover, the results show that companies have a different focus on each online media; sustainability marketing communications are different on Facebook and blogs. Similar to companies, customers also have different preferences on different social platforms. Huang et al. (2019) analyzed participants' reactions to different message formats and content types that spread sustainability knowledge. According to the findings, people browse information on Twitter; however, they seek particular advice related to sustainability knowledge on LinkedIn. Moreover, when information is presented in an infographic, it creates more engagement than a text format.

Sustainability is becoming a fundamental value of competitiveness for companies around the world. Göçer and Tuğrul (2014) analyzed the social media usage of brands to convey their sustainability messages. More specifically, they examined social media communication strategies focusing on sustainability in an emerging market on Facebook, Twitter, and corporate websites through content analysis. According to the findings, brands convey information pertaining to sustainability based on social and economic aspects. The terms "energy", "innovation", "quality", "project" and "social responsibility" are predominantly utilized in messages. However, the "sustainability" term is rarely used. The study proposed using the keyword "sustainability" in messages since it refers to the general concept of sustainability and facilitates the dissemination of messages. It is also stated that the economic dimension is the most preferred concept of sustainability among brands. These findings may provide critical implications in building sustainable strategies for brands in social networks.

Khan et al. (2019) studied how Web Atmospheric Cues, such as visuals, information, ethics, social, and security affect consumer behavior and perception on social media in terms of sustainable marketing strategies. The theoretical aspects of the study argued that it is necessary to know that each social media platform has specific performance and usability criteria based on which cues are applied.

In another study, consumer sentiments toward 26 global green brands were investigated by sentiment analysis. The research focused on FMCG brands because of the daily interaction of 
consumers with products. The analysis of user-generated tweets containing selected brand names shows that tweets related to products and their functions are used more often than sustainability tweets. This may be due to consumers' nature; they become more responsive when a product or brand directly affects them. This fact also explains why there are fewer tweets about companies' green activities than other topics (Resnik \& Koklič, 2018). Another study regarding brands' sustainable strategies was conducted by Jones et al. (2013). The findings reveal that Facebook pages of the UK's top ten retail companies make a limited attempt to develop engagement with their followers in a sustainable manner. The primary focus of Facebook posts is marketing and sales promotions. The retailers mostly persuaded followers to consume rather than encourage them to consider sustainability.

Martínez-Navalón et al. (2019) addressed social media's relationship to environmental sustainability in the food and beverage industry. The outcome of the undertaken study shows that enhancing followers' confidence in a restaurant will have a determinative influence in achieving successful environmental sustainability campaigns. Moreover, environmental sustainability is influenced by continuance intention, which means that customers' intention to continue to follow the brand on social networks affects environmental sustainability. As sustainability is one of people's major concerns, it is recommended that brands may plan their communication strategies via social networks. These firms' strategies influence customers' satisfaction, which, in turn, develops firms' sustainable performance (Abbas et al., 2019).

Hasbullah et al. (2020) investigated spreading brand messages through user-generated content (UGC), particularly focused on sustainable fashion consumption. UGC may have more influence than other media sources due to its creation and dissemination by consumers, which is considered a trusted source ( $\mathrm{Chu} \& \mathrm{Kim}, 2011)$. It is advisable for companies to give weight to content creation and encourage consumers to participate in content creation. UGC practices can establish a robust relationship between companies and consumers. Pilăr et al. (2019) analyzed the main topics related to sustainability by using hashtag analysis on Twitter. Based on 414,926 Twitter interactions, key areas in the sustainability field have been identified: Environmental Sustainability, Renewable energy and Climate change, Sustainability awareness, Innovative Technology, Food Sustainability, and Green Architecture. The main contribution of this paper is to guide brands in designing comprehensive sustainable strategies with consumers' voices.

Overall, eleven articles focusing on the general marketing strategies of brands are summarized in this section. Most of the studies examined the ways brands use social media in implementing green marketing strategies. In this context, they investigated the evaluation of companies' green marketing strategies and also analyzed and compared green marketing strategies. A considerable body of articles focused on how green marketing strategies affect consumer behavior and perception, such as consumers' reactions to different message formats and content types, consumer sentiments towards brands' strategies, and spreading brand messages through user-generated content. The determination of the key areas in the sustainability field, the most used terms in sustainability messages, and the frequency of using these messages are other significant findings.

\subsubsection{Determinants of consumer's green purchasing behavior}

The second theme that can be distinguished among the analyzed studies is the determinants of consumer's green purchasing behavior. Green purchasing behavior can be described as a combination of factors that reflect concerns about environmental issues on purchasing behavior (Uddin \& Khan, 2018). Zahid et al. (2018) highlighted that consumers' environmental concerns are reflected in their purchasing decision. The analysis of collected survey data shows that although green product purchasing decisions are mainly driven by environment-related behaviors, individuals' concern about product benefits and social factors surrounding the environmental consciousness in society also play an essential role in green product purchase intention. 
On the contrary, environmental concern is not significantly associated with green purchasing behavior, according to Gandhi \& Sheorey (2019). Findings from the survey with professionals aged 28-36 suggested that companies may display an ethical image and target consumers who take cognizance of ethical values in their purchasing decisions. As a result of the multiple regression analysis, ethics has the most robust relation with green consumer behavior compared to environmental awareness and social influence.

Sogari et al. (2017) confirmed the moderating role of social media use between sustainability and consumers' purchasing behaviors. Their results highlighted the rise of environmental awareness due to social media; this is also reflected in the buying behavior.

Peer influence is also another factor affecting green purchasing behavior. Zhao et al. (2019) studied Chinese consumers' behavior regarding environmentally sustainable apparel (ESA) consumption and revealed that consumers' interaction with social networks and their colleagues directly influences them to make sustainable purchases. Gonzalez-Lafaysse \& Lapassouse-Madrid (2016) stated that the most important concern in purchasing environmentally friendly products is price.

Byrum (2019) analyzed the effectiveness of various media formats such as news releases, articles, and advertisements; media sources such as business and consumer; and the use of sentiment in creating eco-purchasing involvement. The result indicates that using a consumerto-consumer news release and article has superiority in stimulating environmental purchasing participation. However, advertising is not as effective as other media formats in eco-purchasing. Moreover, there is no noticeable difference in influencing the eco-purchasing decision, whether the source of CSR information was businesses or consumers and whether this source was presented with sentiment.

Lu and Miller (2019) also demonstrated the impact of social media posts on green product sales. The "green product" term used by the American Marketing Association in 1992 refers to environmentally friendly products (Zahid et al., 2018). Lu and Miller (2019) found that posts on social media affect sales among Loyalty Reward Program (LRP) members. All analyzed post types - environment, health, and price are all significant and positively affect green retail sales. Moreover, compared to short-term LRP members, long-term LRP members spend more money responding to health posts on social media. In contrast, long-term LRP members do not spend more than short-term members regarding price and environmental-related posts.

All seven studies demonstrate the determinants of consumer's green purchasing behavior. The main determinants are individuals' concerns about product benefits, environment-related behaviors, social factors, environmental awareness, peer influence, and price. The effects of various media formats and various social media post types in creating eco-buying involvement were also analyzed topics. Besides, there are mixed results regarding environmental concern as a determinant of purchasing decision.

\subsubsection{Brand promotion strategies}

The third theme that emerges from the analysis of collected data is brand promotion strategies. Social media promotions have a significant role in customers' decisions. Thus, this section is dedicated to papers investigating green promotion strategies of brands. Antonella et al. (2019) studied retailers' social media communication used to promote healthy food products. An analysis of Twitter messages from the top 36 European retailers shows that the larger retailers pay less attention to healthy food promotion, unlike smaller retailers. Tweets about general health and sustainability are the main topics of healthy food issues.

Another study on communication strategies based on the environmental theme was conducted by Gonzalez-Lafaysse and Lapassouse-Madrid (2016). This study explored how Facebook plays a vital role in promoting a socially responsible image in one of the leading retail chains. The posts on social media that adhere to social responsibility are among the most posted and 
engaged themes. Discussing new forms of consumption and promoting the social responsibility credentials of the company constituted a big part of published posts on the brand's Facebook page. Furthermore, environmentally-friendly practices and corporate social responsibility topics were not neglected and elicited meaningful discussions. While sustainable development posts were generally well-received by followers, some of them refused to accept responsibility for the environmental damage from their purchases in their comments. It should also be kept in mind that if environmentally conscious messages are perceived as promoting commercial concerns, they may likely be criticized by customers and fail.

Ahmed et al. (2019) studied the impact of social media advertising on building brand sustainability for fast-moving consumer goods (FMCG), finding that social media is an effective communication tool for building brand sustainability. Lee and Park (2016) also support this finding. The scholars confirmed that promotion on social media is an influential factor for a sustainable brand.

In conclusion, four articles focused on the green promotion strategies of brands. One article compared retailers' social media posts on promoting products. Another study investigated the effect of different social media communication strategies in promoting a socially responsible image and argued that environmentally conscious messages should not be perceived as a commercial to be successful. Two other studies in this theme highlighted the importance of social media advertising for building brand sustainability.

\subsubsection{Raising environmental awareness}

The fourth main topic that can be distinguished is raising environmental awareness. Raising environmental awareness is one of the main factors that can contribute to sustainable consumption behavior. Sustainable consumption behavior is defined as "a consumer's wise balance of financial responsibility, environmental stewardship, social equity, and sustenance of personal health" (Lee et al., 2016). Biswas and Roy (2018) identified the positive impact of the usage of social networking technology on sustainable consumption behavior. Awais et al. (2020) addressed the potential relationship between sustainable consumption behavior and e-mavenism on social media websites. E-mavens refer to people who not only collect information but also spread acquired knowledge. They are active customers-looking for discount coupons, comparing stores, and bargains to obtain the best deals through social media. The result confirmed that there is a significant and positive impact of e-mavenism on sustainable consumption.

Topal et al. (2020) analyzed the impact of one of the most significant greenwashing events of the decade, the Volkswagen emission crisis, on online consumer engagement. The study emphasized that although there is a positive approach to green products, consumers' attitudes towards greenwashing may differ in different countries.

Austin and Gaither (2016) investigated how corporate social initiatives (CSIs) of Coca-Cola influence audience response to its social media posts on sustainability. Within the scope of CSR, CSI was indicated as a whole system that includes CSM, cause promotion, corporate philanthropy, community volunteering, cause-related marketing, and socially responsible business practices (Kotler \& Lee, 2005). The findings show that although Corporate Social Media posts are posted more than any other CSI type, the most engaging tweets in terms of generating public comments, favorites, and retweets among the followers are focused on cause promotion. Another contribution of this study was to classify CSI types by topic. One-third of posts are dedicated to the topic of well-being; women and water topics follow it. The results of the study emphasize the need for brands to consider corporate social initiatives. Kang and Kim (2017) researched the relationship between CRM techniques and perceived customer retention orientation of green brands through social media.

Brands should not communicate with their customers through social media solely for their public image; they should provide eco-education and raise environmental awareness among 
customers. Vanko and Zaušková (2019) show that not many brands use social media in this manner. Ineffective traditional marketing strategies and the growing social media base should motivate brands to implement new eco-friendly marketing strategies to raise public awareness. This implication is also supported by Sogari et al. (2017).

Eco-friendliness is also another factor in raising environmental awareness. According to Twitter data mining, Blasi et al. (2020) noticed that consumers expect brands to be environmentally responsible on social media. This is due to an increase in consumers' perception of eco-friendliness.

Shen et al. (2020) argued that social media activities affect people's adoption of sustainable and responsible behavior. Minton et al. (2012) explored the differences in social media motives for participating in sustainable behaviors among different social networks and countries. Responsibility motives were positively associated with recycling on Twitter; on the contrary, they were negatively associated on Facebook. Also, findings show that each country has distinctly different motives for sustainability.

Young et al. (2018) researched the impact of social media messages on consumers' food waste behavior and found that these calls affect consumers' food waste reduction. The authors pointed out that companies can influence consumers' pro-environmental behaviors by sending messages through social media.

Barboza and Filho (2019) explained which values perceived by consumers influence their intention to use green applications. The results demonstrate two different groups: technological consumers - focusing on applications performance and ease of use; green consumers - using green applications due to environmental concern. The study explored the differences between US and Brazilian consumers' consumption. While consumers from the US showed more biospheric and social concerns, Brazilian consumers presented more egoistic values (selfish and individualistic) and focused more price ranges.

To conclude, the fourth main topic contains twelve articles. A significant number of articles investigated the impact of social media on consumers' behavior. Two articles explored the impact of the usage of social networks on sustainable consumption behavior. Eco-friendliness, consumers' attitudes towards greenwashing, social media motives for participating in sustainable behavior, influence of corporate social initiatives on sustainability are other key topics. One of the most significant implications is the importance of raising environmental awareness among customers.

\section{CONCLUSION AND DIRECTIONS FOR FURTHER RESEARCH}

This study marks the first systematic effort at reviewing the articles studying the green marketing concept through social network activities. As a result, a clear and comprehensive overview of the subject was created. The study covered 31 articles, listed bibliometric data of articles, and summarized extracted articles based on four main thematic foci: brand general marketing strategies, brand promotion strategies, factors influencing consumer behavior, and raising environmental awareness.

The paper presents some insights and contributions for scholars and the business world. First, this study gives clear directions to the growing interest in green marketing in terms of implications for marketers. That means that the interest in the topic is rapidly increasing, confirming that implementing green marketing concepts is not just a temporary trend; it is also a leading issue in planning, developing, and marketing goods and services.

When the articles are analyzed by topic, it is seen that most of the studies discuss general marketing strategies of brands and raising environmental awareness topics; there is less interest by scholars in analyzing brand promotion strategies. Hence, this topic can be considered in future 
studies. Furthermore, the conducted systematic literature review may create opportunities for further research on the subject. This research shows the importance of green marketing topic, especially in the strategies implemented by companies.

In terms of implications for scholars, this research provides a comprehensive theoretical framework. Based on the review, a number of research gaps were identified. In accordance with research gaps, the following questions may be the subject of future research:

- What type of content and format that is used on social media related to green marketing is engaging for customers?

- What type of green marketing related content generates the highest engagement (number of likes, shares, and comments) in terms of communication (image, video, text, and infographics)?

- What type of green marketing activities on social media is undertaken in terms of achieving strategic aims?

- What type of content has an influence on consumers in terms of green marketing related topics?

- What type of content has a positive effect on environmental problems?

- What are the differences in consumers' attitudes on green marketing related topics?

- What are the differences in engagement between green marketing related content and other content?

- What type of impact do green marketing activities on social media have on consumer loyalty? Given the results of these findings, some limitations should be considered. Although the search strategy used is as detailed as possible, some research that is not available in English may have been ignored. Moreover, I acknowledge that different databases other than Scopus could be considered to identify studies included in the systematic literature review.

\section{References}

Abbas, J., Mahmood, S., Ali, H., Raza, M.A., Ali, G., Aman, J., Bano, S., \& Nurunnabi, M. (2019). The effects of corporate social responsibility practices and environmental factors through a moderating role of social media marketing on sustainable performance of business firms. Sustainability (Switzerland), 11(12). https://doi. org/10.3390/SU11123434

Ahmed, R.R., Streimikiene, D., Berchtold, G., Vveinhardt, J., Channar, Z.A., \& Soomro, R.H. (2019). Effectiveness of online digital media advertising as a strategic tool for building brand sustainability: Evidence from FMCGs and services sectors of Pakistan. Sustainability (Switzerland), 11(12). https://doi.org/10.3390/su10023436

Antonella, S., Aldo, B., \& Arianna, R. (2019). Food retailing marketing management: social media communication for healthy food. International Journal of Retail \& Distribution Management, 47(9), 928-956. https://doi. org/10.1108/IJRDM-08-2018-0178

Austin, L.L., \& Gaither, B.M. (2016). Examining public response to corporate social initiative types: A quantitative content analysis of Coca-Cola's social media. Social Marketing Quarterly, 22(4), 290-306. https://doi. org/10.1177/1524500416642441

Awais, M., Samin, T., Gulzar, M.A., Hwang, J., \& Zubair, M. (2020). Unfolding the association between the big five, frugality, e-mavenism, and sustainable consumption behavior. Sustainability (Switzerland), 12(2). https://doi. org/10.3390/su12020490

Barboza, M.N.L., \& Filho, E.J.M.A. (2019). Green consumption values in mobile apps. Journal of International Consumer Marketing, 31(1), 66-83. https://doi.org/10.1080/08961530.2018.1490052

Biswas, A., \& Roy, M. (2018). Technology acceptance perception for promotion of sustainable consumption. Environmental Science and Pollution Research, 25(7), 6329-6339. https://doi.org/10.1007/s11356-017-0964-4

Blasi, S., Brigato, L., \& Sedita, S.R. (2020). Eco-friendliness and fashion perceptual attributes of fashion brands: An analysis of consumers' perceptions based on twitter data mining. Journal of Cleaner Production, 244. https:// doi.org/10.1016/j.jclepro.2019.118701

Byrum, K. (2019). "Hey friend, buy green": Social media use to influence eco-purchasing involvement. Environmental Communication, 13(2), 209-221. https://doi.org/10.1080/17524032.2017.1308404

Chu, S.-C., \& Kim, Y. (2011). Determinants of consumer engagement in electronic word-of-mouth (eWOM) in social networking sites. International Journal of Advertising, 30(1), 47-75. https://doi.org/10.2501/ IJA-30-1-047-075 
Dangelico, R.M., \& Vocalelli, D. (2017). "Green marketing”: An analysis of definitions, strategy steps, and tools through a systematic review of the literature. Journal of Cleaner Production, 165, 1263-1279. https://doi. org/10.1016/j.jclepro.2017.07.184

Fuller, D.A. (1999). Sustainable marketing: Managerial-ecological issues. Sage Publications.

Gandhi, A., \& Sheorey, P. (2019). Antecedents of green consumer behaviour: A study of consumers in a developing country like India. International Journal of Public Sector Performance Management, 5(3-4), $278-292$. https://doi.org/10.1504/IJPSPM.2019.101061

Göçer, A., \& Tuğrul, T.O. (2014). How brands communicate sustainability messages in emerging markets: A content analysis based on corporate websites and social media. In Handbook of research on developing sustainable value in economics, finance, and marketing (pp. 47-62). https://doi.org/10.4018/978-1-4666-6635-1.ch004

Gonzalez-Lafaysse, L., \& Lapassouse-Madrid, C. (2016). Facebook and sustainable development: A case study of a French supermarket chain. International Journal of Retail and Distribution Management, 44(5), 560-582. https://doi.org/10.1108/IJRDM-01-2015-0012

Gusenbauer, M., \& Haddaway, N.R. (2020). Which academic search systems are suitable for systematic reviews or meta-analyses? Evaluating retrieval qualities of Google Scholar, PubMed, and 26 other resources. Research Synthesis Methods, 11(2), 181-217. https://doi.org/10.1002/jrsm.1378

Hasbullah, N.N., Sulaiman, Z., \& Mas'od, A. (2020). User-generated content sources: The use of social media in motivating sustainable luxury fashion consumptions. International Journal of Scientific and Technology Research, 9(3), 5208-5214. https:/www.scopus.com/inward/record.uri?eid=2-s2.0-85082727232\&partnerI $\mathrm{D}=40 \& \mathrm{md} 5=2 \mathrm{c} 07 \mathrm{cbb} 2 \mathrm{f} 2 \mathrm{e} 92 \mathrm{~b} 6 \mathrm{dd} 69 \mathrm{dd} 98 \mathrm{~d} 2269 \mathrm{aae} 1$

Huang, L., Clarke, A., Heldsinger, N., \& Tian, W. (2019). The communication role of social media in social marketing: a study of the community sustainability knowledge dissemination on LinkedIn and Twitter. Journal of Marketing Analytics, 7(2), 64-75. https://doi.org/10.1057/s41270-019-00053-8

Jones, P., Clarke-Hill, C., Comfort, D., \& Hillier, D. (2013). Sustainability: UK retailers and social media. World Review of Entrepreneurship, Management and Sustainable Development, 9(4), 460-474. https://doi. org/10.1504/WREMSD.2013.056756

Kang, J.-Y.M., \& Kim, J. (2017). Online customer relationship marketing tactics through social media and perceived customer retention orientation of the green retailer. Journal of Fashion Marketing and Management: An International Journal, 21(3), 298-316. https://doi.org/10.1108/JFMM-08-2016-0071

Khan, A.A., Wang, M.Z., Ehsan, S., Nurunnabi, M., \& Hashmi, M.H. (2019). Linking sustainability-oriented marketing to social media and web atmospheric cues. Sustainability (Switzerland), 11(9). https://doi. org/10.3390/su11092663

Kotler, P., \& Lee, N. (2005). Best of breed: When it comes to gaining a market edge while supporting a social cause, "corporate social marketing" leads the pack. Social Marketing Quarterly, 11(3-4), 91-103. https:/doi. org/10.1080/15245000500414480

Kumar, A., Bezawada, R., Rishika, R., Janakiraman, R., \& Kannan, P.K. (2016). From social to sale: The effects of firm-generated content in social media on customer behavior. Journal of Marketing, 80(1), 7-25. https://doi. org/10.1509/jm.14.0249

Lee, D.J., Bahl, A., Black, G.S., Duber-Smith, D.C., \& Vowles, N.S. (2016). Sustainable and non-sustainable consumer behavior in young adults. Young Consumers, 17(1), 78-93. https://doi.org/10.1108/YC-08-2015-00548

Lee, Y.-C. (2017). Corporate sustainable development and marketing communications on social media: Fortune 500 enterprises. Business Strategy and the Environment, 26(5), 569-583. https://doi.org/10.1002/bse.1936

Lee, Y.-K., \& Park, J.-W. (2016). Impact of a sustainable brand on improving business performance of airport enterprises: The case of Incheon International Airport. Journal of Air Transport Management, 53, 46-53. https://doi.org/10.1016/j.jairtraman.2016.01.002

Lu, Q.S., \& Miller, R. (2019). How social media communications combine with customer loyalty management to boost green retail sales. Journal of Interactive Marketing, 46, 87-100. https://doi.org/10.1016/j.intmar.2018.12.005

Martínez-Navalón, J.G., Gelashvili, V., \& Debasa, F. (2019). The impact of restaurant social media on environmental sustainability: An empirical study. Sustainability (Switzerland), 11(21). https://doi.org/10.3390/su11216105

Minton, E., Lee, C., Orth, U., Kim, C.-H., \& Kahle, L. (2012). Sustainable marketing and social media. Journal of Advertising, 41(4), 69-84. https://doi.org/10.1080/00913367.2012.10672458

Moher, D., Liberati, A., Tetzlaff, J., Altman, D.G., \& Grp, P. (2009). Preferred reporting items for systematic reviews and meta-analyses: The PRISMA statement (Reprinted from Annals of Internal Medicine). Physical Therapy, 89(9), 873-880. https://doi.org/10.1371/journal.pmed.1000097

Pilăr, L., Stanislavská, L.K., Pitrová, J., Krejčí, I., Tichá, I., \& Chalupová, M. (2019). Twitter analysis of global communication in the field of sustainability. Sustainability (Switzerland), 11(24). https://doi.org/10.3390/ su11246958

Polonsky, M.J. (1994). An introduction to green marketing. Electronic Green Journal, 1(2). https://doi.org/10.5070/ g31210177 
Resnik, S., \& Koklič, M.K. (2018). User-generated tweets about global green brands: A sentiment analysis approach. Market-Trziste, 30(2), 125-146. https://doi.org/10.22598/mt/2018.30.2.125

Shen, S., Sotiriadis, M., \& Zhou, Q. (2020). Could smart tourists be sustainable and responsible as well? The contribution of social networking sites to improving their sustainable and responsible behavior. Sustainability (Switzerland), 12(4), 1-21. https://doi.org/10.3390/su12041470

Siddaway, A.P., Wood, A.M., \& Hedges, L.V. (2019). How to do a systematic review: A best practice guide for conducting and reporting narrative reviews, meta-analyses, and meta-syntheses. Annual Review of Psychology, 70, 747-770. https://doi.org/10.1146/annurev-psych-010418-102803

Sogari, G., Pucci, T., Aquilani, B., \& Zanni, L. (2017). Millennial generation and environmental sustainability: The role of social media in the consumer purchasing behavior for wine. Sustainability (Switzerland), 9(10). https://doi.org/10.3390/su9101911

Topal, İ., Nart, S., Akar, C., \& Erkollar, A. (2020a). The effect of greenwashing on online consumer engagement: A comparative study in France, Germany, Turkey, and the United Kingdom. Business Strategy and the Environment, 29(2), 465-480. https://doi.org/10.1002/bse.2380

Uddin, S.M.F., \& Khan, M.N. (2018). Young consumer's green purchasing behavior: Opportunities for green marketing. Journal of Global Marketing, 31(4), 270-281. https://doi.org/10.1080/08911762.2017.1407982

Vanko, M., \& Zaušková, A. (2019). Raising public awareness of eco-innovations through social media. Proceedings of the European Conference on Innovation and Entrepreneurship, ECIE, 2, 1076-1085. https://doi. org/10.34190/ECIE.19.167

We are social \& Hootsuite. (2020). The global state of digital, Global report (Q4 update). Retrieved on 7 November 2020 from https:/www.slideshare.net/DataReportal/digital-2020-october-global-statshot-report-october-2020-v01.

Young, C.W., Russell, S.V., Robinson, C.A., \& Chintakayala, P.K. (2018). Sustainable retailing - Influencing consumer behaviour on food waste. Business Strategy and the Environment, 27(1), 1-15. https://doi. org/10.1002/bse.1966

Zahid, M.M., Ali, B., Ahmad, M.S., Thurasamy, R., \& Amin, N. (2018). Factors affecting purchase intention and social media publicity of green products: The mediating role of concern for consequences. Corporate Social Responsibility and Environmental Management, 25(3), 225-236. https://doi.org/10.1002/csr.1450

Zhao, L., Lee, S.H., \& Copeland, L.R. (2019). Social media and Chinese consumers' environmentally sustainable apparel purchase intentions. Asia Pacific Journal of Marketing and Logistics, 31(4), 855-874. https://doi. org/10.1108/APJML-08-2017-0183 